Proc. Indian Acad. Sci. (Earth Planet. Sci.), Vol. 98, No. 3, October 1989. pp. 247-254.

(C) Printed in India.

\title{
Observations of mid-tropospheric circulation from water vapour radiances of polar orbiting satellites
}

\author{
M S NARAYANAN, P K PAL, P C JOSHI, M M ALI and BABY SIMON \\ Meteorology and Oceanography Division, Space Applications Centre, Ahmedabad 380053, \\ India \\ MS received 27 February 1989; revised 28 August 1989
}

\begin{abstract}
Water vapour tracers can provide useful information on winds at $\sim 500 \mathrm{mb}$ by observing the $6.7 \mu$ radiances. This fills the data gap in the cloud motion winds provided by conventional meteorological geostationary satellites. There is no geostationary satellite at present over the Indian Ocean with $6.7 \mu$ imaging capability to provide mid-tropospheric winds. The potentials of $6.7 \mu$ radiances, available from polar orbiting satellites, for mid-tropospheric circulation features have been examined in this study. Tiros- $\mathrm{N}$ satellite data of May 1979 and ECMWF level-IIIb wind data were analysed to relate the radiances with the streamlines. We find that the radiances of $6.7 \mu$ from orbiting satellites agree well with the wind field.
\end{abstract}

Keywords. Polar orbiting satellite; mid-tropospheric streamlines; water vapour radiances.

\section{Introduction}

METEOSAT (over Europe) and GOES (over USA) geostationary satellites have shown the capability to provide mid-tropospheric winds by tracking radiances at the 6.7 $\mu$ water vapour absorption band (Eigenwillig and Fischer 1982; Stewart et al 1985). This information fills the data gap between $200 \mathrm{mb}$ and $850 \mathrm{mb}$ at which cloud vector winds are available from geostationary meteorological satellites. Over the oceans around the Indian subcontinent, cloud vector winds at two levels are provided by INSAT-1B, but winds at no other levels are available. For the study of tropical weather systems information of winds at these two levels alone is insufficient (Joshi et al 1987).

In the absence of a geostationary satellite over the Indian ocean with water vapour channel imaging, we have attempted to relate mid-tropospheric circulation to water vapour structures observed from the $6.7 \mu$ radiance of the polar orbiting satellite. Some attempts have been made earlier (Strenka et al 1973; Rodgers et al 1976) to determine mid-tropospheric streamlines around North America using data from Nimbus $6.7 \mu$ water vapour channel. Our present study is also relevant in the context of delineating the $500 \mathrm{mb}$ ridge during April over Indian longitudes (Shukla and Mooley 1987; Joshi et al 1989).

We have used the FGGE data of May 1979 from TIROS-N satellite's high resolution infra-red sounder (HIRS) for water vapour radiances. For studying the corresponding circulations, the European Centre for Medium Range Weather Forecasting's (ECMWF) 400 and $500 \mathrm{mb}$ wind fields were used. In the next section we describe the details of the data used and the method. The results of one month's data are presented in $\S 3$. Section 4 summarizes the conclusions of the present work. 


\section{Data and methodology}

Level-Ib HIRS data of the sun-synchronous TIROS-N satellite supplied by NOAA of USA were used. TIROS-N satellite has a repeativity of $12 \mathrm{~h}$. Only the day time data for the region equator to $30^{\circ} \mathrm{N}$ and $45^{\circ} \mathrm{E}$ to $100^{\circ} \mathrm{E}$ were used. The HIRS system is a 20-channel instrument sounding the atmosphere at different wavelengths in the visible, the near- and the thermal-infra-red regions of the spectrum. The sensors of HIRS measure the reflectance in the visible and the emitted radiance of the earth and atmosphere in different absorption bands of water vapour, carbon dioxide and ozone, besides at a few atmospheric window regions. The resolution of the HIRS sensors is $18 \mathrm{~km}$ at nadir degrading to about $40 \mathrm{~km}$ at the extreme ends $(\sim 1000 \mathrm{~km}$ from the sub-satellite point). This instrument has three channels in the water vapour absorption band in the wavelength range $6.5 \mu$ to $8.5 \mu$. The response of these channels peaks at the surface, $\sim 700 \mathrm{mb}$ and $\sim 500 \mathrm{mb}$ with broad weighting functions (figure 1). The weighting functions show the relative contribution of each layer to the measured radiance at a particular channel (Smith 1968). HIRS channel number 12 corresponding to one of the water vapour channel's radiance at $6.7 \mu$ (weighting function peaking at $\sim 500 \mathrm{mb}$ ) was used for the the present study. In conjunction with this, data of HIRS channel number 8 (providing radiance of the atmospheric window at $11 \mu$ ) were used to delineate the presence of clouds that disturb the water vapour channel. The water vapour data for cloudy regions (delineated by the $11 \mu$ channel) were excluded from the analysis.

Level-Ib data were in the form of digital counts on tapes for all 20 channels, with appropriate latitude and longitudes. These count values can be converted to radiances (and through the inverse Planck function to equivalent black-body brightness temperatures, $T_{B}$ ) using a cubic polynomial and the on-board calibration coefficients

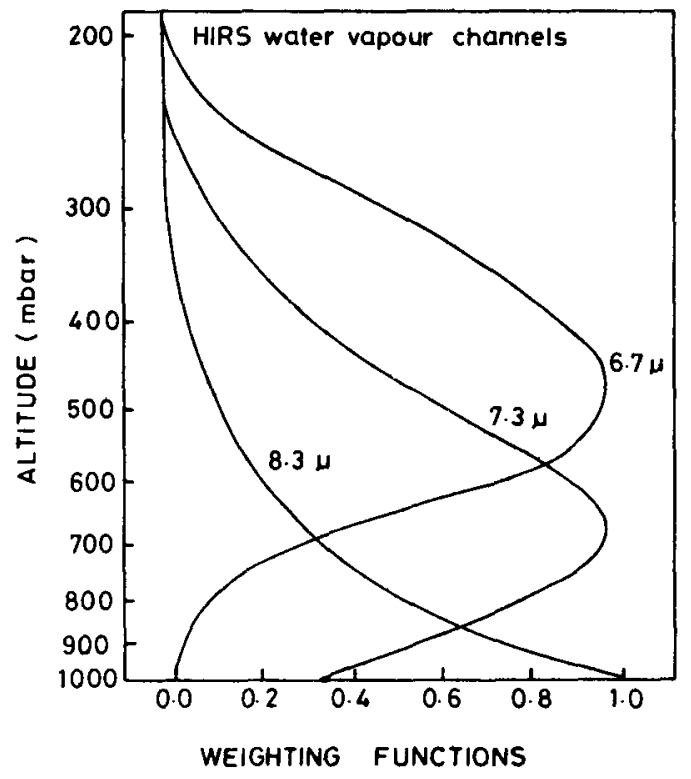

Figure 1. Normalized weighting functions as a function of altitude for the three water vapour channels of HIRS/TIROS-N. 
provided along with the data (Kidwell 1986). For the present study the brightness temperatures, for channels 8 and 12 , were averaged over each $0.5^{\circ} \times 0.5^{\circ}$ latitudelongitude grid. A thermal map for channel 12 was generated by assigning different symbols to different ranges of temperatures. The minimum temperature mapped was $215 \mathrm{~K}$ designated by the symbol ' 1 '. Subsequent symbols were assigned at intervals of $1 \mathrm{~K}$, with the following sequence of symbols: $1,2, \ldots, 9, \mathrm{~A}, \mathrm{~B}, \mathrm{C}, \ldots, \mathrm{Z}, \mathrm{a}, \mathrm{b}, \mathrm{c}, \ldots, \mathrm{q}$. Thus a total of fifty classes were considered. Temperatures less than $215 \mathrm{~K}$ were all assigned the symbol ' 1 ' and temperature higher than $265 \mathrm{~K}$ were assigned the symbol '*'

In the corresponding $11 \mu$ window channel maps, brightness temperatures less than $290 \mathrm{~K}$ were considered cloudy. The corresponding data points were designated cloudy in the $6.7 \mu$ water vapour map with the symbol '? The places where no data were available are shown by the symbol ' $\%$ ' on these maps.

Daily water vapour thermal maps (at 6.7 $\mu$ ) for the period May 9-31, 1979, were thus generated. The $400 \mathrm{mb}$ and the $500 \mathrm{mb}$ circulation maps from the ECMWF level-IIIb data set were also generated on the same scale as these thermal maps for the convenience of overlay. The ECMWF level-111b winds are available at $1.875 \mathrm{deg}$ lat.-long. grid for the globe, twice a day at 15 pressure levels from surface to $2 \mathrm{mb}$ for FGGE period. The two maps were then analysed to study the influence of the circulation on the water vapour structures.

\section{Results and discussion}

The $6.7 \mu$ channel equivalent brightness temperature is modulated primarily by the quantity of the water vapour in the intervening atmosphere. To examine the sensitivity of the radiances or brightness temperatures to changes in relative humidity, we simulated the brightness temperatures using radiative transfer formulations (Schanda 1986) with different humidities. It was noticed that with a reduction of water vapour by $40 \%$ in the middle troposphere there was a reduction in brightness temperature of only $\sim 1 \mathrm{~K}$. However, a drier mid-troposphere (and higher water vapour at lower levels) produced in $T_{B}$ a change of $\sim 10-15^{\circ} \mathrm{C}$. Drastic changes in total water vapour in the neighbouring regions were rare.

We have neglected the observed brightness temperature gradient changes in $6.7 \mu$ due to atmospheric temperature changes. Thus all the changes in $T_{B}$ are considered as an outcome of water vapour inhomogeneities. We further assume that water vapour irregularities were aligned along the streamlines.

During the early period of the investigation (May 9-12), there was a tropical cyclone over Bay of Bengal. The region had varying amounts of cloudiness which progressively moved northwards. Even after the decay of the cyclone, some unorganised clouds persisted over the Bay of Bengal. Thus the regions for which some inferences could be made from the present analysis are only over the Arabian peninsula, the Arabian Sea and the Indian peninsula.

An examination of the maps of 9-13 May showed that west of the cyclone the brightness temperature decreases, i.e. the water vapour increases with time. This suggests that the cyclonic circulation had increased the water vapour content in the mid-troposphere in those regions. Similarly, during this period, over the Arabian sea, eastwards of Arabia the temperatures were relatively higher, indicating that dry air 
from Arabia was pervading over the Arabian sea mid-troposphere. Both these situations were well represented by thermal maps, and the water vapour isotherms closey followed the wind direction.

The weighting function characteristics suggest that for the tropics the $6.7 \mu$ channel data were better representative of $400 \mathrm{mb}$ than the $500 \mathrm{mb}$ circulation. Our analysis also showed that the thermal maps are more consistent with $400 \mathrm{mb}$ wind pattern. We observed that the thermal maps show better resemblance to circulation patterns with a lag of one day. We show examples of three representative days that broadly relate the thermal maps with the previous day's mid-tropospheric circulation.

Figure 2 shows the $6.7 \mu$ thermal map for 14 May and figure 3 shows the corresponding $400 \mathrm{mb}$ wind field on 13 May reproduced from ECMWF level-IIIb data set. The northerly winds over the Arabian sea are well represented by the

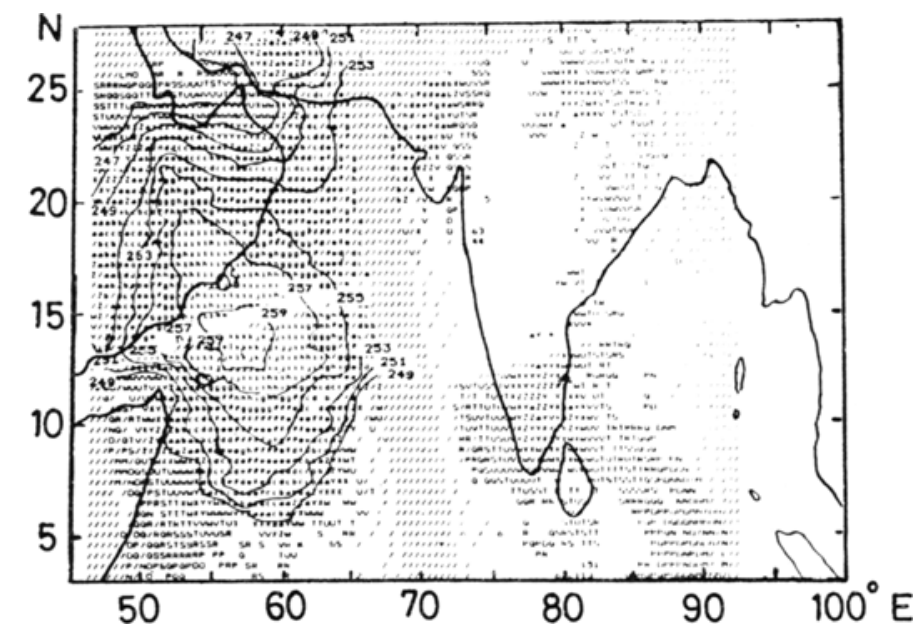

Figure 2. $6.7 \mu$ thermal map of HIRS for 14 May 1979.

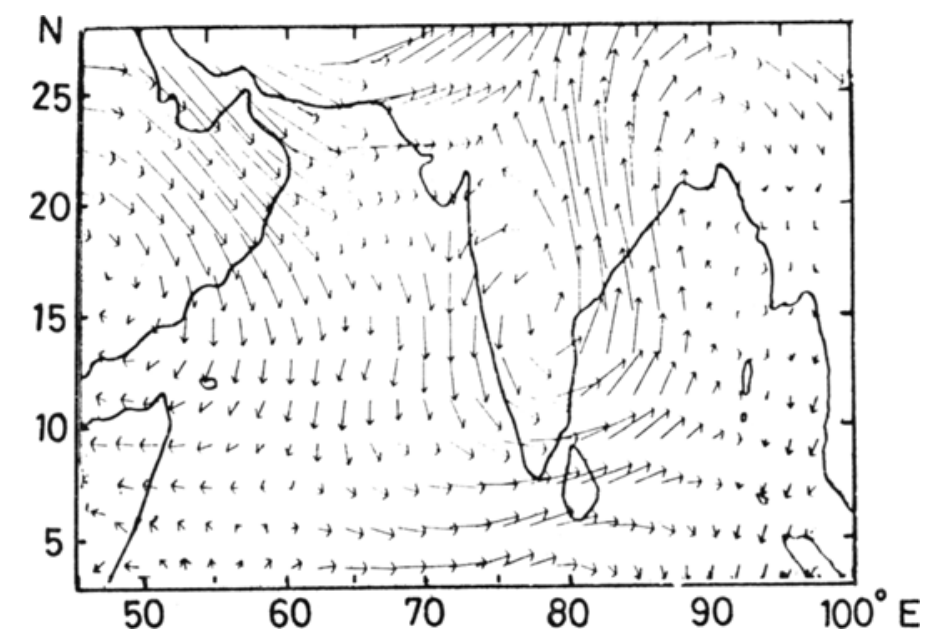

Figure 3. Wind vector plot from ECMWF level-IIIb for 13 May 1979. 
isotherms running north-south (NS) over the central Arabian sea. The weak easterly flow off Somalia is represented by the bending of the NS isotherms. Similarly, the trough in the extreme north around Pakistan is represented by the curvature of isotherms.

The thermal map for 19 May is shown in figure 4 and figure 5 shows the corresponding wind field for $18 \mathrm{May}$. The easterly wind over central Arabian sea is well represented by the isotherms in figure 4 where they are oriented zonally in contrast to a meridional orientation a week ago. The orientation of the isotherms in the Arabian sea is also explained by weaker northerly winds. Similarly, the streamlines over north eastern India in figure 5 are well represented by inclined isotherms around that region.

A similar day-to-day analysis of the thermal maps and the wind fields for May

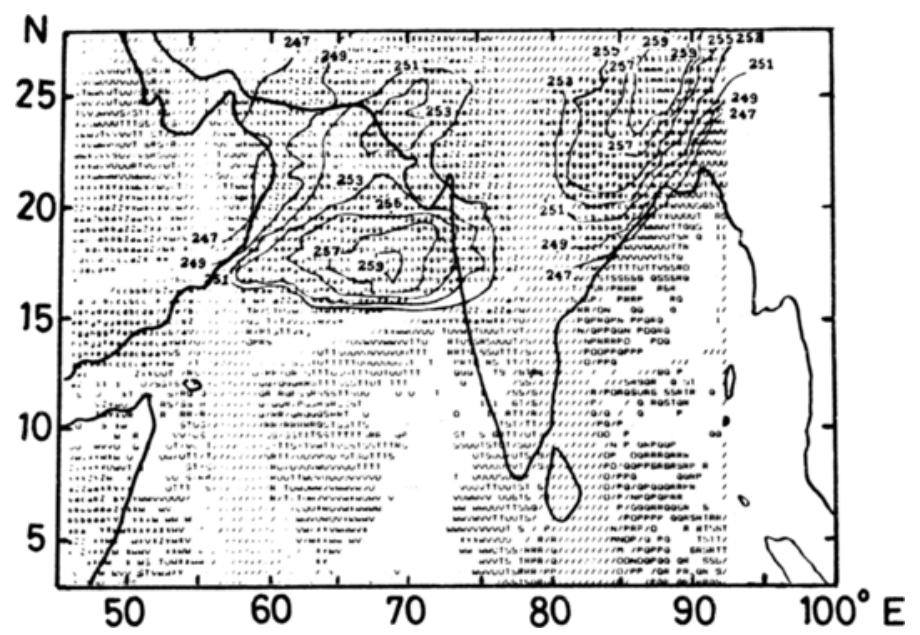

Figure 4. $67 \mu$ thermal map of HIRS for 19 May 1989.

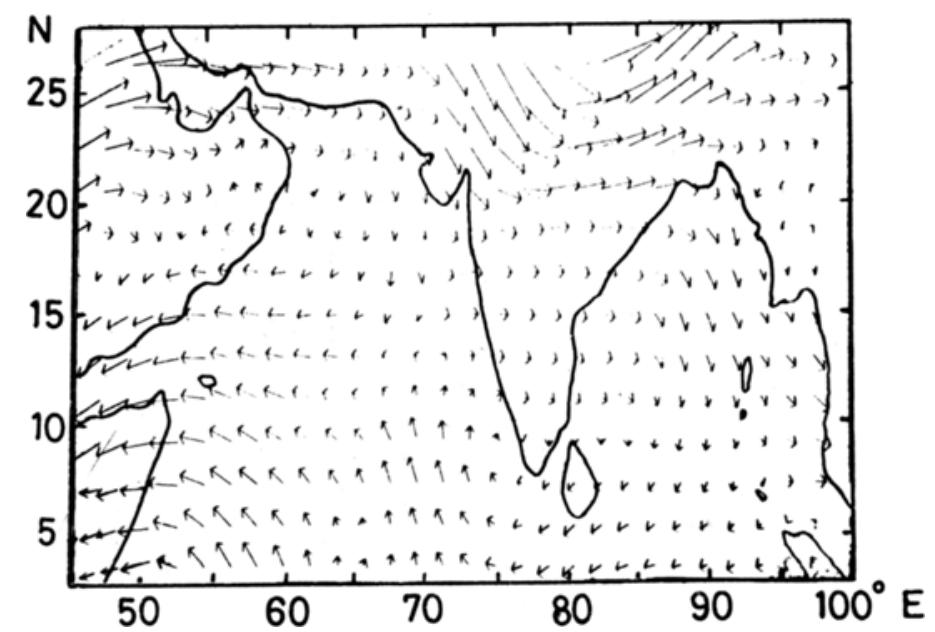

Figure 5. Wind plot from ECMWF level-llib data for 18 May 1979. 
showed that the water vapour brightness temperature contours broadly align themselves along streamlines. But, there were a few cases where the correspondence was not very satisfactory. Figure 6 shows the thermal map for 23 May and figure 7 shows the wind field for the same day. The anticyclonic flow over the Arabian sea is well reproduced by the isotherms. But, according to the thermal map the streamlines were expected to be oriented in the NS direction. The actual observed winds (figure 7) were almost easterlies in the west central Arabian sea. Strong northerlies are observed only at eastern longitudes where no water vapour data were available. At lower latitudes over the western Arabian sea the isotherms seem to match the streamlines better. Along the west coast the gradients do not show the patterns seen in the observed wind fields.

The mid-troposphere in May had cyclonic circulation up to the middle of 14 May.

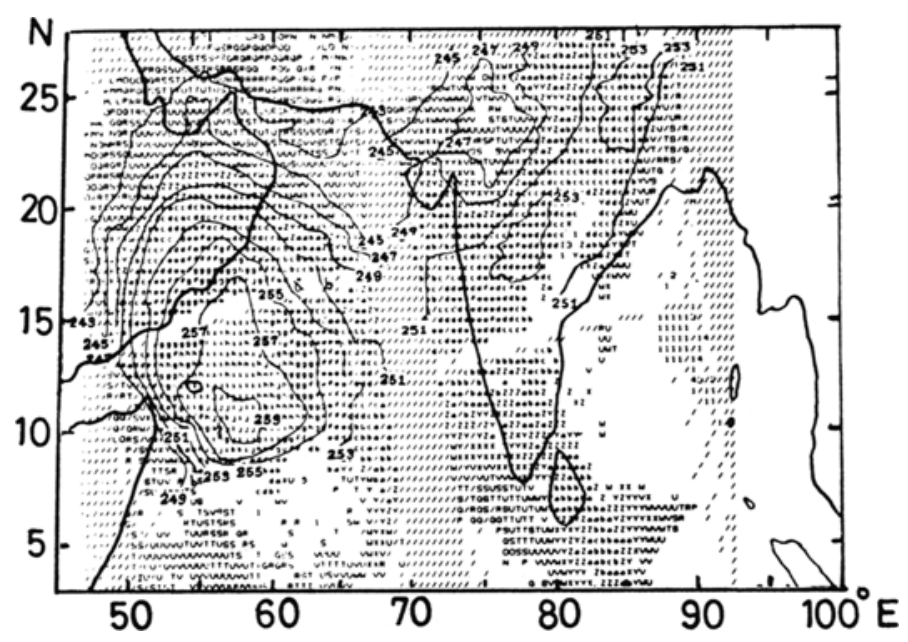

Figure 6. 6.7 $\mu$ thermal map of HIRS for 24 May 1979.



Figure 7. Wind plot from ECMWF level-IIIb data for 23 May 1979. 
An anticyclone centred round the Arabian peninsula was present throughout the month, which showed a prominent northerly structure over the Arabian sea. Another anticyclone later developed over the Bay of Bengal by 17 May and merged with a westward moving cyclone by $25 \mathrm{May}$. In association with this circulation the thermal maps showed the following patterns:

9-12 May: South of $14^{\circ} \mathrm{N}$ little cloud free data were available. The higher isotherms, over both the Arabian peninsula and India, showed an orientation in the SSW-NNW direction.

13-16 May: There were no data over India and to its south. But sufficient data were available over the Arabian sea and Arabia. The isotherms were organized around a high at about $55^{\circ} \mathrm{E}$ in the latitude range $10^{\circ}-14^{\circ} \mathrm{N}$. The structure was consistent with the anticyclonic circulation around this region.

17-19 May: During this period the NS axis of the isotherms gradually turned to become EW by 19 May. By this time sufficient data were available over the Indian sub-continent and its adjoining areas.

20-27 May: The orientation of the isotherms was NS and between them were embedded two 'highs'. This structure oscillated in an east-west direction depending on the satellite path. This is the period when both the anticyclones in the wind flow had merged. The NS orientation of the isotherms over the whole region (wherever data were available) matches well with the anticyclonic structure.

\section{Conclusions}

We have presented examples where the water vapour radiances observed in the $6.7 \mu$ imageries were aligned along the streamlines of the mid-tropospheric circulation. There exists potential for single imageries of $6.7 \mu$ water vapour channel from polar orbiting satellites for inferring mid-tropospheric circulation, over cloud-free areas. Using the conventional land station data and these maps, it will be possible to better delineate the streamlines of $400-500 \mathrm{mb}$ region over the west coast of India and Arabian sea and thus determine more accurately the ridge position during the month of April.

\section{Acknowledgements}

We thank our colleague Mr D G K Murty for useful discussions relating to HIRS data preprocessing.

\section{References}

Eigenwillig $\mathrm{N}$ and Fischer $\mathrm{H} 1982$ Determination of mid-tropospheric wind vectors by tracking pure water vapour structures in METEOSAT water vapour image sequences; Bull. Am. Meteorol. Soc. 63 44-58

Joshi P C, Kishtwal C M, Narayanan M S, Sharma O P and Upadhyay H C 1987 Assessment of the use of satellite derived winds in monsoon forecasting using a general circulation model; Adv. Space Res. $7353-356$ 
Joshi P C, Simon B and Patra S K 1989 Use of NOAA temperature sounding data in long range forecasting of south-west monsoon rainfall; Indian J. Radio Space Phys. 18 117-119

Kidwell K B 1986 NOAA polar orbiter data user's guide. US Dept. of Commerce, Washington, Chapter 4, p. 24

Rodgers E B, Salomonson V V and Kyle H L 1976 Upper tropospheric dynamics as reflected in Nimbus-4 THIR $6.7 \mu$ data; $J$. Geophys. Res. $815749-5758$

Schanda E 1986 Physical fundamentals of remote sensing (Berlin: Springer-Verlag)

Shukla J and Mooley D A 1987 Empirical prediction of the summer monsoon rainfall over India; Mon. Weath. Rev. 115 695-703

Smith W L 1968 An improved method for calculating tropospheric temperature and moisture from satellite radiometer measurements; Mon. Weath. Rev. $96387-396$

Stewart T R, Hayden C M and Smith W L 1985 A note on water vapour wind tracking using VAS data on McIDAS; Bull. Am. Meteorol. Soc. 66 1111-1115

Strenka J, Allison L J and Salomonson V V 1973 Application of Nimbus-4 THIR 6.7 $\mu$ observations to regional and global moisture and wind field ăhalysis; J. Appl. Meteorol. 12 386-395 